\title{
EEG correlates of reinforced behavioral inhibition ${ }^{1}$
}

\author{
NORMAN WEINBERGER ${ }^{2}$, LORNE YEUDALL, AND DONALD B. LINDSLEY, UNIVERSITY OF CALIFORNIA, IRVINE
} AND UNIVERSITY OF CALIFORNIA, LOS ANGELES

Three cats, bearing chronically implanted cortical electrodes, were trained in an instrumental vigilance situation to inhibit licking a foodcup for $15-25$ sec prior to the onset of a stimulus signalling availability of a milk reward. Electrocortical activity following attainment of stable inhibition of licking was characteristically desynchronized, differing little from pre-inhibitory activity. On some occasions, motor quiescence was highly correlated with a 14-16/sec rhythm. However, since inhibition of licking and/or lack of movement also occurred in the absence of this waveform, it probably does not reflect neural processes necessary for behavioral inhibition. Enhanced cortical synchrony during behavioral inhibition. reported by other investigators may indicate a lowering of arousal level which often accompanies behavioral inhibition rather than the neural processes underlying inhibition itself.

The search for neural substrates of behavior has often focused upon electroencephalographic changes recorded during task performance or inhibition of performance. With regard to the latter, investigators concerned with EEG correlates of Pavlovian internal inhibition have reported a predominance of cortical synchrony, i.e., slower waves, spindles, or both. Such a relationship between internal inhibition and synchrony has been reported in several situations, e.g., extinction (Kogan, 1960), satiation (Rowland \& Goldstone, 1963), habituation (Hernandez-Peon, 1960), classical differential discrimination (Gluck \& Rowland, 1959). These findings support the belief that cortical synchrony reflects the action of neural mechanisms governing behavioral inhibition.

All of the above situations engender inactivity and relaxation, suggesting that cortical synchrony may be a reflection of lowered arousal level rather than of brain mechanisms underlying behavioral inhibition itself. The present study was undertaken to investigate this possibility. An instrumental vigilance paradigm was used in order to maintain a relatively high degree of arousal while seeking electrocortical correlates of behavioral inhibition.

\section{Method}

Three adult cats, bearing chronically implanted, stainless steel skull electrodes, were maintained at $85 \%$ of ad lib weight and trained to inhibit licking in a vigilance situation. The apparatus consisted of a dimly illuminated 18 in. cubic chamber with a Lucite foodcup mounted on a $4 \times 5$ in. black panel affixed to the rear wall. Foodcup licks were detected by a GrasonStadler drinkometer, and recorded by a Davis Scientific Instruments $\mathrm{Co}$. cumulative recorder. Illumination of a row of $106 \mathrm{~W}$ lamps, mounted 8 in. above the cup, served as a discriminative stimulus. The training chamber was enclosed within an audiometry room(Industrial Acoustics) and a white masking noise was present throughout each session.

The cats were trained to lick the foodcup for $0.3 \mathrm{cc}$ of milk when the row of lamps was illuminated (S+). Inhibitory training was initiated following initial training on a schedule of continuous reinforcement. The first lick following $S+$ onset was rewarded and terminated S+. Following the ensuing burst of consummatory licking, S- began. This condition consisted of the continued absence of $\mathrm{S}+$, and varied randomly within a session from 15-25 sec (mean of $20 \mathrm{sec}$ ). Each lick during S- reset the S- timer, thus delaying the next scheduled onset of St. As training progressed, S+ duration was decreased to a maximum of $0.8 \mathrm{sec}$; licks having a longer latency were not rewarded, as they occurred during the $S-$ period. A daily session consisted of $50 \mathrm{~S}+$ presentations.

Electrocortical activity (ECOG) was recorded via a cable attached to the S's skull pedestal; it was so suspended as not to interfere with movements. ECoGs were recorded on a Grass IIID electroencephalograph with a band pass of 1-75 Hz. Recordings were made irregularly during initial phases of the experiment and routinely when stable inhibition of licking had been established. Resulis

All three $\mathrm{Ss}$ learned to respond to $\mathrm{S}+$ within $0.8 \mathrm{sec}$, and to inhibit licking during $S-$. The numbers of sessions required to reach stabilized inhibition (three consecutive sessions without improvement) were 12,23 , and 28 for the three cats. Behavior early in training was characterized by many short bursts of licking during S- (Fig. 1A). Ss would often leave the cup and walk around the chamber following such a burst of unrewarded licks, and might therefore miss or respond to late to the next S+ (Fig. 1B). As training continued and inhibition during S- improved, the cats remained facing the cup, although postural adjustment movements and abortivelicks were often seen. In the terminal stages of training, as inhibition stabilized, these movements occurred occasionally, but Ss' behavior characteristically consisted in sitting quietly facing the cup, licking rapldly at $S+$ onset, and then resuming the initial posture.

ECoGs recorded during all phases of training were characteristically of low-voltage, fast activity, that is, cortical activation or desynchronization. Frontal, temporal, and occipital electrodes neither differed greatly, nor varied consistently, from this type of record, even during stabilization of inhibition of licking. However, there were occasions in the later stages of the experi- 
ment during which behavior was highly correlated with an increase in cortical synchrony. During some periods of motor quiescence, the ECoG was dominated by a highly regular $14-16 / \mathrm{sec}$ rhythm of about $100-125 \mu \mathrm{V}$. The slightest movement resulted in the disappearance of this waveform, and the reappearance of desynchronization $(20-40 / \mathrm{sec}, 50 \mu \mathrm{V})$. One of the most striking examples of this relationship is seen in Fig. 2; the correlation between motor quiescence and the 14-16/sec rhythm was 0.95 for this period of the record. While absence of movement seemed to be necessary for the occurrence of this synchrony, both inhibition of licking and motor quiescence also occurred during desynchronization.

\section{Discussion}

In this experiment, cortical synchrony was not characteristically present during inhibition of licking, although it was sometimes seen during motor inhibition. Unlike most previous studies of the relationship between behavioral inhibition and the ECoG, the present situation required maintenance of a high level of arousal. These considerations suggest that ECoG synchrony probably reflects lowered arousal rather than neural processes governing behavioral inhibition itself (see Weinberger et al, 1967a).

Recent studies have found that when animals remain in an aroused or alerted state, the ECoG is less sensitive than other electrical indices of brain activity. Amygdala fast waves (Pagano \& Gault, 1964), DC shifts

\section{Session 4}

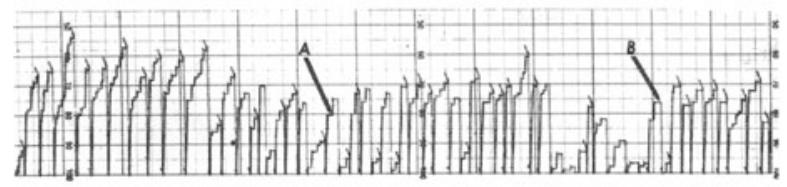

Session 12
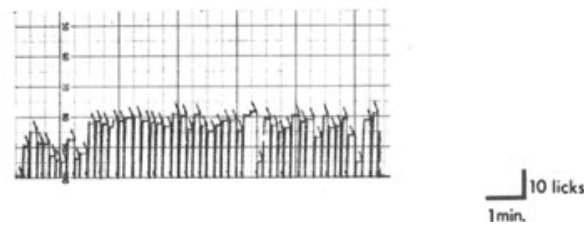

Fig. 1. Records of licking of one cat during early (session 4) and late (session 12) inhibitory training. The cumulative recorder was returned to base at the termination of each $S+$ to facilitate analysis of the degree of inhibition. Slanted lines denote reinforcements. After resetting, the first rapid rise indicates consummatory licking; the number of "steps" thereafter signifies erroneous bursts of licking during $S$-. Upper record, early training; A: a typical burst of licking during $S$-; B: one of several trials during which $S$ was not oriented to the cup, did not lick during $S+$ and was not reinforced. Session 4 required about $18 \mathrm{~min}$, during which the cat reset S. 94 times. Session 12, which shows a typical pattern during good inhibition required only $9 \mathrm{~min}$ and included only 2 resets.

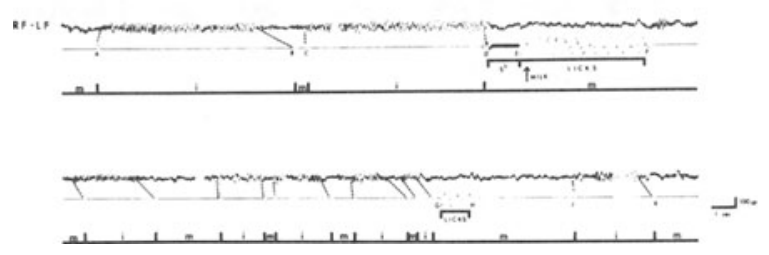

Fig. 2. The relationship between motor quiescence and the ECoG during a period of $50 \mathrm{sec}$. The lower record is continuous with the upper row. The top line is the ECoG recorded between the right and left frontal cortices. The middle record is a stimulus marker which was energized by an observer, without knowledge of the ECoG, during periods of motor quiescence. The dotted lines connecting these records denote corresponding segments which were correlated $(r=.95)$. The bottom row simply summarizes the signal marker for movement $(\mathrm{m})$ or motor quiescence (i). Note the absence of synchrony druing $S+$ and subsequent licking (starting at $D$ ), and the desynchronization slightly preceding erroneous licks during $\mathbf{S}$ - (G.H).

(Rowland et al, 1967), and recruiting responses (Weinberger et al, $1965,1967 \mathrm{~b}$ ) all vary with behavior in the absence of gross ECoG changes. It is not yet known whether they merely reflect slight changes of arousal in alert animals, or neural processes governing more specific aspects of behavior, e.g., inhibition, attention, and so on.

\section{References}

GLUCK, H. Z. \& ROWLAND, V. Defensive conditioning of electrographic arousal with delayed and differentiated auditory stimuli. Electroenceph. clin. Neurophysiol., 1959, 11, 485-496.

HERNANDEZ-PEON, R. Neurophysiological correlates of habituation and other manifestations of plastic inhibition. Electroenceph. clin. Neurophysiol, 1960, Suppl. 13, 101-114.

KOGAN, A. B. The manifestations of processes of higher nervous activity in the electrical potentials of the cortex during free behavior of animals. Electroenceph. clin. Neurophysiol, 1960, Suppl. 13, $51-64$.

PAGANO, R. R. \& GAULT, F. P. Amygdala activity: a central measure of arousal. Electroenceph. clin. Neurophysiol, 1964, 17, 255-260.

ROWLAND, V., \& GOLDSTONE, M. Appetitively conditioned and drive-related bioelectric baseline shift in cat cortex. Electroenceph clin. Neurophysiol. 1963, 15, 474-485.

ROWLAND, V., BRADLEY, H., SCHOOL, P., \& DEUTSCHMAN, D. Cortical steady potential shifts in conditioning. Cond. Reflex, 1967, 2, 3-22.

WEINBERGER, N. M., VELASCO, M., \& LINDSLEY, D. B. Differential effects of reinforced and non-reinforced stimuli upon electrocortical recruiting responses. Psychon. Sci, 1965, 2, 129-130.

WEINBERGER, N. M., VELASCO, M., \& LINDSLEY, D. B. The relationship between cortical synchrony and behavioral inhibition. Electroenceph. clin. Neurophysiol., 1967a, 23, 297-305.

WEINBERGER, N. M., NAKAYAMA, K., \& LINDSLEY, D. B. Electrocortical recruiting responses during classical conditioning. Electroclin. Neurophysiol, 1967b, in press.

Notes

1. This research was supported in part by Office of Naval Research contract Nonr-233 (32).

2. Research performed during the tenure of NIMH post-doctoral fellowship No. Mh-10, 327. 